\title{
Dialéctica negativa y reflexión crítica: el problema moral en la filosofía y la teoría social de Theodor W. Adorno*
}

\author{
Negative dialectic and critical reflection: the moral problem in \\ the philosophy and social theory of Theodor W. Adorno
}

EZEQUIEL IPAR**

\begin{abstract}
Resumen: La crítica del sujeto moral realizada por Adorno resulta clave para comprender su proyecto filosófico. Por un lado, permite reconstruir los momentos esenciales de su crítica a la filosofía del sujeto. Pero la crítica moral también ofrece la posibilidad de realizar una indagación más formal de su obra, dado que la misma figura como uno de los objetos privilegiados de la Dialéctica Negativa. De este modo, al revisar su crítica moral uno tiene la oportunidad de plantear la difícil pregunta por la forma de esa filosofía que se presenta a sí misma como una dialéctica que exacerba la negatividad del pensamiento.

Palabras Clave: Sujeto - Moralidad - Crítica Dialéctica - Negatividad
\end{abstract}

\begin{abstract}
The criticism of the moral subject by Adorno is crucial to understand his philosophical project. On the one hand, it allows us to reconstruct the essential moments of his critique to the philosophy of the Subject. But moral criticism also offers the possibility of conducting a more formal investigation of his work, given that it is one of the principal objects of the Negative Dialectics. In this way, when reviewing his moral critique one has the opportunity to explore the difficult question of the form of a philosophy that presents itself as a dialectic that exacerbates the negativity of thought.

Keywords: Subject - Morality - Critique - Dialectics - Negativity
\end{abstract}

\section{Introducción}

El propósito de esta contribución, referida a la crítica moral en Adorno, es doble. Por un lado, me interesa reconstruir los elementos esenciales del abordaje que hizo Adorno del problema moral en sus trabajos filosóficos y sociológicos más importantes (Adorno: 1995a, 1995b, 2001). Para avanzar en esa dirección se vuelve decisiva la relación con la filosofía moral de Kant, fundamentalmente porque la crítica moral kantiana aparece como el territorio privilegiado escogido por Adorno para desplegar su propia crítica moral (Adorno, 2001: 15). En un sentido que tendremos que examinar, su reflexión es una crítica de la crítica kantiana.

Recibido: 09/01/2018. Aceptado: 01/07/2018.

* $\quad$ Este trabajo forma parte del proyecto de investigación PIP-CONICET (11220130100054CO): "Dilemas de la democracia y el capitalismo en la Argentina contemporánea".

** Doctor en Filosofía por la Universidade de São Paulo (USP) y doctor en Ciencias Sociales por la Universidad de Buenos Aires (UBA). Profesor en la materia Historia del Conocimiento Sociológico en la Facultad de Ciencias Sociales de la UBA e investigador adjunto en el Consejo Nacional de Investigaciones Científicas y Técnicas (CONICET). Autor de Las corrientes subterráneas de la Escuela de Frankfurt y coordinador del libro colectivo La subjetividad anti-democrática. Sus investigaciones actuales giran en torno a la teoría crítica de la democracia y al pensamiento dialéctico de Adorno. Correo electrónico: ezequielipar@conicet.gov.ar 
Pero el problema moral ofrece una segunda oportunidad teórica que me interesa explorar aquí. Contenido como objeto de la Dialéctica Negativa, el problema moral constituye uno de los tres Modelos conceptuales a partir de los cuales Adorno desarrolla su filosofía madura. De este modo, al revisar la crítica moral de Adorno uno tiene la oportunidad de plantear la difícil pregunta por la forma de esa filosofía que se presenta a sí misma como una dialéctica singular, una dialéctica que piensa a través de la exacerbación de la negatividad. Esta segunda perspectiva, evidentemente, nos pone en relación con Hegel y nos obliga a reflexionar sobre la distancia que lo separa de Adorno o, lo que es lo mismo, sobre la diferencia que existe entre una dialéctica que trabaja la negatividad como medio de producción de una Idea y otra que confronta toda Idea con la negatividad que ella misma provoca, negatividad que la experiencia filosófica tiene que ser capaz de interrogar y expresar.

\section{La moral como modelo de servidumbre}

Axel Honneth ha mostrado recientemente de qué modo la crítica kantiana de las costumbres y la moral tradicional depende de una idea fuerte de libertad reflexiva (Honneth, 2014: 47-52). En la base de esta idea kantiana se encuentran la capacidad que todo individuo tiene para influir sobre su voluntad y tomar decisiones por sí mismo. Ser libre significa en este modelo ético ser capaz de volverse sobre sí para discernir e influir sobre los deseos, las pasiones y las voliciones que circulan en el mundo interno del sujeto. En la teoría de Kant esta capacidad reflexiva de auto-determinación resulta fundamental para la moral, porque ese discernimiento interior es el que nos permite volvernos responsables frente a los otros por nuestros propios actos. Por esto, en este modelo normativo la fundamentación de la autonomía racional del sujeto se vuelve crucial.

En su formulación kantiana, la reflexión hace posible la libertad individual y crea las condiciones para la justificación racional de los principios morales. Ambos procesos van, aparentemente, de la mano. La libertad individual es una condición indispensable para la justificación racional (universalizable) de los principios prácticos y, al mismo tiempo, sólo un orden social justificado racionalmente es capaz de promover a través de sus leyes e instituciones la libertad individual. Este reforzamiento mutuo entre la libertad del sujeto de la reflexión y la racionalidad de las formas de sociabilidad le da forma al círculo de las virtudes racionales. Este círculo, que encontramos ya al comienzo del proyecto kantiano (Kant, 1995), constituye el principal blanco de la crítica de Adorno (2001) a este modelo de filosofía moral. Se puede pensar la crítica de adorno a la moral como un dislocamiento en ese aparente círculo de virtudes racionales, que produce como efecto de esa intervención dos series de problemas: a) el problema de la génesis "abstracta" de la autonomía del sujeto moral; y, b) el problema de las consecuencias potencialmente represivas de la moral racionalizada para la vida del sujeto y la sociedad.

En la interpretación de Adorno (2001: 78-88), la concepción kantiana de la autonomía se vuelve abstracta porque suprime de un modo drástico cualquier influencia del otro en el juicio moral, transformando de ese modo al sujeto racional práctico en un individuo monadológico. Sólo a este sujeto se le atribuye la facultad para descubrir (reflexivamente en sí mismo) el principio de una legislación moral universal, esto es, la facultad moral de pensar bajo la forma universal de una ley que no depende de la contingencia de las inclinaciones o 
los anhelos de felicidad de quienes indagan sobre las cuestiones de la vida práctica (Kant, 2000 [A]: 108-109). De allí que la enseñanza de Kant en este punto sea muy clara: sólo la reflexión que se alcanza en soledad llega hasta la forma de la ley y delimita con seguridad el fundamento de la filosofía moral. Esta filosofía moral, a su vez, pretende proveer todas las condiciones indispensables (la fidelidad a las promesas mutuas, la preservación de la vida, la laboriosidad, el cuidado del bienestar ajeno, etc.) para una vida en común justa y duradera.

Ahora bien, cuando la libertad reflexiva funciona como el único fundamento de la moral, la subjetividad práctica corre el riesgo de anular sus vínculos con la empiricidad y la historicidad. Este carácter abstracto de la subjetividad moral, que instituye un modelo mono-lógico de autonomía ${ }^{1}$, se transforma en uno de los motivos centrales de la crítica adorniana. Para Adorno, en este tipo de fundamentaciones no quedan representados -como se pretende- los juicios de todos los afectados por la ley moral, ya que el ideal del sujeto capaz de "pensar en la forma de la ley universal" termina siendo usado para canalizar prejuicios sociales excluyentes (contra las mujeres, los miembros de otras culturas, etc.). Adorno constata estos prejuicios, por ejemplo, en el contenido de la ética del trabajo que Kant exalta en su fundamentación. Según éste "el mal radical no es otro que la pereza, la imposibilidad de satisfacer el requisito fundamental de la sociedad burguesa" (Adorno, 2001: 131). Para Adorno, que la autonomía del sujeto moral sea abstracta significa que es parcial, ilusoria y abierta a prejuicios que desmienten su pretendida universalidad.

Del otro lado de esta relación entre libertad y sociabilidad racional Adorno encuentra un problema semejante, que va a precipitar al proyecto kantiano en una contradicción. La idea kantiana es muy conocida: sólo descubrimos la esencia de nuestra libertad cuando debemos elegir bajo el escrutinio de nuestra conciencia moral, que nos exige obediencia estricta y el cumplimiento riguroso de la ley. Esto quiere decir, en términos prácticos, que sólo mediante la sujeción (a los principios de la moral) el hombre puede experimentar y realizar la esencia de su libertad. De esa obediencia surgiría el respeto mutuo por el cual cada individuo reconoce a los otros como fines en sí mismos y no como medios de sus propios fines. Pero lo que observa Adorno es que una vez que se activa la reflexión en la interioridad de la subjetividad, el sujeto sólo descubre allí la necesidad de la obediencia y la renuncia, aún allí donde resulta difícil comprender los beneficios de la misma. En esta reflexión moral la renuncia termina transformándose en "algo que existe en sí mismo y es bueno en sí mismo" (Adorno, 2001: 139-140).

Por estos dos motivos, por el carácter abstracto de la fundamentación y la sujeción práctica hacia la que apunta, Adorno piensa que la concepción kantiana de la autonomía subjetiva culmina afirmando -involuntariamente- un modelo represivo de sociabilidad, que desmiente el carácter libre de la determinación de la ley moral, así como la racionalidad que pretende garantizar. Esta asociación entre autonomía y represión, Adorno la encuentra en los propios ejemplos de la Crítica de la Razón Práctica, en los que se puede leer un desajuste entre el horizonte de las observaciones referidas a la existencia de la libertad y el orden de las demostraciones de la necesidad racional de la sujeción moral (Adorno, 1995a: 222 y ss.). De hecho, la sugerencia de que puede existir una contradicción entre la racionalidad de la libertad y la

1 El alcance de esta crítica al "monologismo" de la fundamentación kantiana de la moral permite establecer puntos de contacto con las posiciones de Habermas, cuya ética del discurso rechaza los principios morales que se obtienen por medio de fundamentaciones solipsistas. Sobre este aspecto, la crítica de Habermas al monologismo implicado en el constructivismo moral de Rawls resulta ejemplar (Habermas y Rawls, 1998: 51 y ss.). 
racionalidad de la sujeción es una de las grandes virtudes que Adorno le reconoce a la filosofía moral de Kant, sobre todo cuando recurre a la experiencia concreta para complejizar su planteo trascendental, aproximando de esa manera la reflexión moral a "la realidad de la vida mental en general y las maneras en las que se comportan de hecho las personas" (Adorno, 2001: 130).

Cuando desplegamos esta tensión entre la libertad subjetiva y la objetividad de la ley moral, lo que leemos en Kant es una explicación de la existencia de la libertad que apunta hacia el esclarecimiento de la voluntad de autodeterminación (que puede oponerse a la vigencia de cualquier regla establecida) y una comprensión de la ley moral que depende exclusivamente del sentimiento de culpa. Kant agrega -sin proponérselo- este suplemento externo en el orden a priori de la demostración. Pero por esa vía se termina desatando el nexo inmediato que había ideado entre la libertad de la reflexión y la obediencia a la ley moral, tal como lo calculaba especulativamente la razón pura. Ahora vemos que también podemos conocer a la libertad a través de la experiencia que tenemos de nuestra capacidad para autodeterminarnos. Del mismo modo, podemos conocer a la ley moral en nosotros, no como el fundamento teórico de la libertad sino como la creencia en una falta con el otro de la que nos suponemos responsables. Adorno lee sintomáticamente este hiato de la justificación racional de la moral: por un lado, como el desacuerdo que le puede plantear el individuo a la moral instituida cuando explora capacidades de auto-determinación que no entran en la forma de la auto-sujeción moral; del otro lado, como el descubrimiento de un orden de creencias heterónomas que trabajan ocultas al interior de las justificaciones que el sujeto cree darse libremente a sí mismo al volverse legislador-súbdito de la moral (Adorno, 1995a: 224 y ss.).

Cuando lee a Kant, Adorno lamenta que en la fundamentación de su filosofía moral desaparezca esta diferencia. En cambio, lo que orienta la estrategia de la fundamentación es la huida de las contradicciones y paradojas (Adorno 2001: 67-77) que aparecen en el análisis de la relación entre autonomía individual y justicia racional. Criticar moralmente significa -esto es lo que le critica Adorno a la crítica moral kantiana-distanciarse del círculo de los conflictos y las paradojas de las relaciones prácticas, para intentar subsumir esos conflictos y esas paradojas bajo un principio de resolución universal (que se demuestra falso en cada contacto con la facticidad histórica y social). Se establece así un fundamento imaginario que permite juzgar a todos los conflictos en el sentido de un perpetuo restablecimiento de la relación armónica entre libertad individual y justicia objetiva. Pero el único camino posible para hallar esta armonía, es el abandono de la autonomía de los problemas morales y su sustitución por el primado de la razón teórica, que es la única que conserva la capacidad de darle a la forma subjetiva de sus principios la forma objetiva de una ley general (Kant, 2000 [A]: 112-113).

La primera tesis de Adorno critica esta triple operación: el repliegue sobre la unidad monadológica del sujeto moral, la heteronomía enmascarada como autonomía y la ceguera con respecto a las contradicciones y las paradojas de las decisiones morales. Esa tesis, que contradice el fundamento de la tesis kantiana, dice así: la soberanía de la razón pura en la vida práctica, lejos de garantizar la realización simultánea de la libertad y la sociabilidad racional, termina haciendo de la moral el modelo de la servidumbre voluntaria. La argumentación de Adorno pretende mostrar, siguiendo una nítida línea nietzscheana, que una libertad que se obtiene a través de la supresión en el sujeto de sus pasiones y sus deseos individuales de autodeterminación, no conserva nada que merezca ser llamado con ese nombre. Esto era algo que se dejaba entrever en los propios ejemplos kantianos, en los que ya Schopenhauer descubría 
un resultado negativo para la vida, dado que no existe una "equivalencia real entre la renuncia a los instintos en el presente y la compensación en el futuro" (Adorno, 2001: 139).

En esta interpretación, la libertad que se identifica con la obediencia no debe ser considerada como libertad para el sujeto real, salvo que se pretenda aceptar que su máxima despotenciación, la destrucción de su capacidad de obrar, pueda coincidir con su libertad. Con esta crítica, que depende también de Freud, Adorno descubre en las paradojas de la fundamentación kantiana del sujeto moral las huellas que revelan el imperio de un poder opresivo que se ejerce irracionalmente por encima de los individuos.

\section{La moral individualizada como modelo de la crítica: más allá de la voluntad de poder}

En la introducción a Minima Moralia Adorno ofrece una perspectiva distinta sobre el valor y el lugar de la crítica moral en la modernidad tardía. Contrariando ahora la acusación nietzscheana que condenaba en la Gaya Ciencia a la moral como ciencia melancólica o ciencia de la impotencia, Adorno va a reconsiderar los problemas del discurso moral y los va a reponer como problemas esenciales de la crítica social. En Minima Moralia, la propia idea de crítica queda asociada internamente con la moral, específicamente con la capacidad de crítica moral del individuo. El pasaje programático de Adorno es muy claro: "a la vista de la unidad totalitaria que anuncia directamente la eliminación de la diferencia como sentido, es posible que temporalmente una parte de la fuerza social liberadora se haya replegado en la esfera del individuo. En ella persiste, no sólo con mala conciencia, la teoría crítica” (Adorno, 1995b: 12). A su vez, en la Dialéctica Negativa Adorno vuelve a enfatizar esta posición que encuentra "en la aspiración socialmente insatisfecha del individuo" la esencia de una reflexión moral que es capaz de diagnosticar "lo malo de la universalidad" (Adorno, 1995a: 278).

Esta lectura contradice, al menos parcialmente, la reconstrucción que hemos hecho de la primera tesis adorniana. Hemos mostrado que para Adorno la reflexión moral individual es un saber pretendidamente racional, que se transforma en un procedimiento de justificación de creencias que son socialmente falsas y perjudiciales para la libertad. La moral era, en ese primer sentido, el modelo de la servidumbre voluntaria. Pero descubrimos ahora en una obra fundamental de Adorno sobre esta problemática una tesis que claramente se contrapone a la anterior. Leemos en distintos fragmentos de Minima Moralia el esfuerzo por mostrar de qué modo la reflexión individual referida a los problemas morales de las sociedades capitalistas avanzadas puede servir como modelo práctico de la crítica a la dominación. En los sucesivos pasajes en los que se refiere a la posibilidad de pensar relaciones no-deformadas, Adorno critica la destrucción abstracta de la reflexión moral, que culmina generalizando el perspectivismo posesivo de la auto-conservación capitalista o propiciando la restauración de valores feudales (Schweppenhäuser, 2004: 335-337).

Esta posición de Adorno redescubre los momentos críticos de Kant y no está muy lejos de la posición de Habermas, ya que ambos encuentran la necesidad de realizar indagaciones sobre la función social de la moral como elemento fundamental para la crítica de la dominación (Habermas, 1994: 57 y ss.). La crítica que elabora reflexivamente el sujeto moral se opone ahora al conformismo hedonista de las sociedades capitalistas y a la vigencia de valores (de clases) que esconden su carácter violento. Esta segunda tesis de la dialéctica 
negativa de la moral dice así: sólo la perseverancia de la reflexión moral puede confrontar con éxito los efectos de la cosificación capitalista de la cultura, abriendo el auténtico camino para un pensamiento emancipador.

Si bien ambas tesis son contradictorias, esta segunda tesis, que niega a la primera, conserva al mismo tiempo algo de ella, fundamentalmente porque corrige la idea inicial sobre la reflexión moral. De hecho, lo que esta segunda tesis conserva es la negatividad de la primera, la denuncia de las operaciones que hacen del discurso moral un discurso de la servidumbre de los hombres. A lo largo de Minima Moralia esta corrección se vuelve infinita. Destaco aquí, esquemáticamente, cuatro modificaciones que Adorno practica en su propia crítica moral sobre la idea tradicional (kantiana) de reflexión moral.

En primer lugar, Adorno redefine la concepción del distanciamiento de la reflexión que se dispone a tratar asuntos morales. El distanciamiento puro de la reflexión trascendental aparece rechazado y es pensado como una fantasía o una ilusión que prepara las condiciones de la otra gran fantasía del discurso moral tradicional, la fantasía de la neutralidad absoluta. Frente a esta pretensión, Adorno va a sostener, en cambio, un distanciamiento que está siempre ya implicado en su objeto. Esto significa, por un lado, que para las situaciones que despiertan efectivamente la reflexión moral resulta imposible conseguir un distanciamiento absoluto o purificado de cualquier interés:

Para el que no sigue la corriente existe el peligro de que se tenga por mejor que los demás y de que abuce de su crítica de la sociedad como ideología al servicio de su interés privado. (...) El que vive distanciado se halla tan enredado como el que está activamente comprometido; frente a éste no tiene otra ventaja que la consciencia de estar enredado y la suerte de la minúscula libertad que supone reconocerse de tal manera. Su propio distanciamiento con respecto a la actividad mundana es un lujo, que sólo la actividad mundana derriba. Por eso cada impulso por sustraerse porta los rasgos de lo negado. La frialdad que se tiene que mostrar no es distinta de la frialdad burguesa. Incluso donde se protesta yace lo universal dominante oculto en el principio monadológico." (Adorno, 1995b: 27)

Si la pretensión de un distanciamiento puro aparece como ideológica, la posibilidad de un distanciamiento - de la reflexión moral- que se reconoce implicado en su objeto, abocado a las controversias prácticas que le dieron origen, adquiere ahora para Adorno un valor positivo. Sin sobredimensionar su eficacia práctica, el reconocimiento de la implicación de la crítica moral en "lo universal dominante" es el que permite tomar distancia de los intereses, los deseos y las pasiones tal como existen en la sociedad, allí donde aparecen fetichizados y confundidos con lo que es bueno o justo para todos (Adorno, 2001: 142); pero no para independizarse absolutamente de esa componente afectiva y relacional, sino para redescubrir otros deseos y otros juegos afectivos susceptibles de ejercer una influencia moral.

En segundo lugar, la reflexión moral que intenta recuperar Adorno no se despliega como un movimiento de reconducción al origen monadológico del sujeto. Por el contrario, Adorno piensa el repliegue de la reflexión moral como temporalidad singular, como un repliegue del pensamiento y la acción sobre temporalidades diferenciadas. La reflexión moral, en este sentido, no necesita una "esfera de los orígenes absolutos en el sujeto" (Adorno, 1995a: 222), 
sino un tiempo diferente al de las relaciones prácticas instituidas que se rigen por los imperativos, socialmente configurados, de la auto-conservación. Replegarse sobre otros ritmos de los acontecimientos, alcanzar diferentes tiempos para diferentes decisiones prácticas, ése es -para Adorno- el auténtico repliegue sobre sí de la reflexión moral. Este plegarse sobre sí de la reflexión moral es el que la va a situar en los márgenes del Estado y del mercado, lo que aquí quiere decir, en los márgenes de la aceleración de la temporalidad mercantil y estatal.

En tercer lugar, la reflexión moral que le interesa a Adorno deja de estar obsesionada con un juicio práctico-trascendental que depende de la capacidad para formarse una representación acabada de la sociedad justa. En este sentido, la reflexión moral que aparece en Minima Moralia no depende de una teoría comprensiva de la Justicia. Lo que busca Adorno aquí son formas afirmativas de solidaridad (Menke, 2006b: 73-79), que aparecen reconstruidas a través de análisis sociales micrológicos. Esos análisis se concentran en la búsqueda, en el contexto del capitalismo tardío, de aquellas disposiciones que les permiten a los sujetos experimentar el sufrimiento ajeno y compartir (miméticamente) el juicio del otro frente a ese sufrimiento: "el dolor debe cesar/este dolor es la injusticia". La normatividad que se insinúa en esta reflexión no exige en abstracto conservar a la sociedad justa, sino hacer cesar el sufrimiento físico y psíquico del otro. En la Dialéctica Negativa Adorno vuelve sobre este planteo:

El momento corporal recuerda al conocimiento que el sufrimiento no debe ser, que debería cambiar (daß Leiden nicht sein, daß es anders werden solle). "El dolor exige: cesa”. (...) Semejante institución tendría su telos en la negación del sufrimiento físico aún del último de sus miembros y de las formas interiores de la reflexión de ese sufrimiento. Tal es el interés de todos, únicamente realizable mediante una solidaridad transparente hacia ellos mismos y hacia todo lo viviente. (Adorno, 1995a: 203-204)

Con esta concepción de la solidaridad, evidentemente, Adorno se aleja de cualquier escepticismo moral. En este aspecto, tiene razón Forst cuando sostiene que al criticar la "injustica de la justicia", esto es, al explicitar la dialéctica normativa por la cual "la ceguera de un afán individual de justicia" se transforma ella misma en lo dañino y lo injusto, la crítica de Adorno "es primariamente una crítica de la falta de justicia en nombre de la justicia" (Forst, 2015: 183-184). Las razones que expone Forst en este análisis sirven para precisar los motivos de la dialéctica de la moral en Adorno, porque identifican adecuadamente uno de los blancos de su crítica: el narcisismo y la auto-suficiencia de la razón en los asuntos prácticos. Efectivamente, para Adorno "tener razón y actuar correctamente son dos cosas distintas" (Forst, 2015: 183). Pero para trazar esta diferencia Adorno no recurre, como lo hace el principio de justificación de Forst, a la constante renovación crítica de las pretensiones de la justicia a las que puede llegar una auto-reflexión racional que es capaz de reconocer la finitud en la justicia instituida. En cambio, Adorno establece una relación muy precisa entre la normatividad moral y la corporalidad ${ }^{2}$, que es la que le permite al sujeto

2 El análisis de la compasión resulta clave para esta indagación normativa, que parte del individuo y lo trasciende a través de la corporalidad. Ver, Adorno y Horkheimer (1994), pp. 144 y ss. López Álvarez (2001) estudia la importancia de la corporalidad en la crítica moral y política que Marx y Adorno le dirigen al formalismo kantiano y a la totalidad ética de Hegel en un sentido que coincide y amplia el argumento que desarrollamos, necesariamente de un modo esquemático, en este trabajo. 
de la reflexión moral salir del monologismo e insertarse conflictivamente en los diferentes contextos prácticos en los que descubre la necesidad de hacerle justicia a los individuos.

A partir de este vínculo entre solidaridad y corporalidad, Adorno continua con su crítica de la autonomía del sujeto abstracto, para el que la autonomía "sólo es pensable al precio del distanciamiento frente a la naturaleza propia y exterior", que suprime "los objetivos eróticos, la necesidades pulsionales del Eros" y termina fundiendo esa fuerza pulsional "con la violencia, el sometimiento y las fantasías de apoderamiento referidas al propio yo y a los otros" (Zamora, 2003: 238). Pero ahora se enfatiza otro aspecto, puesto que se indica que lo que destruye esa subjetividad moral abstracta son los afectos de afinidad y simpatía que están en la base de las posibilidades de una relación justa con los otros (Adorno y Horkheimer, 1994: 140 y ss.). Como vemos en el pasaje que acabamos de citar, es "el momento corporal el que le recuerda" al sujeto el contenido singular del imperativo moral (Schweppenhäuser, 2004: 344-347), que queda olvidado en la reflexión abstracta y generalizadora de la justicia.

La última determinación -extraña dentro de la tradición kantiana- que Adorno utiliza para repensar a la reflexión moral es la generosidad, entendida como una capacidad indispensable de la intersubjetividad moral. En Minima Moralia aparece indirectamente esta figura intersubjetiva a través del análisis de la inactualidad de la práctica del regalar y la creciente disolución de la singularidad del regalo (Adorno, 1995b: 46-47). No voy a entrar aquí en todos los detalles, que por cierto son muy elocuentes, de estos materiales de la reflexión que ofrecen un diagnóstico crítico de las relaciones morales vigentes, una imagen plástica de la "imposibilidad de la moral" bajo la constitución actual de las sociedades del capitalismo tardío. Me detengo sólo en la consideración positiva de la práctica del regalar: la capacidad de dar algo singular a alguien particular, a cambio de nada. Luego de diferenciar claramente al regalar de la caridad ("beneficencia administrada") y la donación ("consideración justa que humilla"), Adorno describe a esta práctica con un particular acento moral:

El verdadero regalar tenía su felicidad en la imaginación de la felicidad del obsequiado. Significaba elegir, dedicar tiempo, salirse de las propias preferencias, pensar al otro como sujeto: lo contrario del olvido. (Adorno, 1995b: 47)

A través de la generosidad, ejemplificada aquí en la práctica del regalar, Adorno reescribe las determinaciones más importantes del compromiso moral: la libertad de elección, la especificidad de un tiempo para la singularidad de una decisión y la auténtica capacidad práctica para salirse de las preferencias propias. Todos estos son requisitos para poder tomar en cuenta al otro (no olvidarlo) y tratarlo como un sujeto (digno de reconocimiento individual). Si ser capaces de tomar al otro como sujeto significa decidir hacerse responsable por el propio modo de tratar a la individualidad libre de los otros, Adorno nos muestra ahora que reconocer al otro como sujeto también implica una cierta capacidad, la capacidad para experimentar más allá de las preferencias propias la singularidad del otro, que en el análisis del regalar se revela como una capacidad moral: "toda relación no deformada -continua Adorno- es un regalar, quien guiado por la lógica de la consecuencia se vuelve incapaz de eso, se convierte en cosa, se congela" (Adorno, 1995b: 47).

Ahora bien, en esta perspectiva no se deriva de la crítica al consecuencialismo moral el salto a la frialdad superior de lo incondicionado de la razón, sino que se descubre en la generosidad 
una capacidad subjetiva imprescindible para la moralidad. Apartándose de quienes afirman que la generosidad no es algo que pueda exigirse moralmente, Adorno muestra que sin la gramática de la generosidad las exigencias morales carecerían de sentido y de fuerza. Esta condición, sin embargo, inscribe entre las exigencias de la reflexión moral un principio de irreciprocidad ${ }^{3}$, ya que nos obliga a pensar a la moral más allá de la lógica de la utilidad común y/o de la igualdad formal de los derechos mutuamente reconocidos. La crítica moral de Adorno critica de este modo a cualquier subjetividad endurecida frente a los otros, tanto la subjetividad calculadora del utilitarismo, como la subjetividad ciega frente a lo individual del rigorismo. En ambas subjetividades encuentra un proceso de "endurecimiento" (Zamora, 2010: 251-252) que, en esta interpretación filosófica y sociológica, aparece como la causa de la imposibilidad de la verdadera reflexión moral, aquello que Adorno suele asociar con las condiciones subjetivas que hicieron posible el "genocidio administrativo" (Zamora, 2010: 248; Zamora y Maiso, 2012).

Indirectamente reseñamos las dos grandes diferencias de Adorno con las revisiones clásicas de la filosofía práctica kantiana dentro de la teoría crítica (Habermas y Forst). A diferencia de Habermas, que también criticó el monologismo de la fundamentación kantiana a partir de una concepción intersubjetiva del discurso moral (Habermas, 1994), Adorno acepta dentro de la esfera autónoma de la reflexión moral la heteronomía que proviene de los afectos. Por otro lado, y en este caso en contraposición con Forst, que también somete a una revisión crítica al distanciamiento del trascendentalismo moral de Kant a partir de una justificación que se presenta siempre como contextual (Forst, 1996), Adorno defiende a la irreciprocidad de la generosidad como momento necesario de la disposición moral.

No obstante, a pesar de estas diferencias, es evidente que ahora estamos lejos del ambiente vitalista o utilitarista implícito en la primera crítica a la filosofía moral kantiana, que pensaba a la moral como modelo de la servidumbre voluntaria. En esta segunda tesis la reflexión moral (implicada en las paradojas de su objeto, plegada sobre temporalidades singulares, corporal e impulsada por la gramática de la generosidad) aparece como modelo de la crítica social contra los efectos cosificadores del mundo administrado.

\section{La producción normativa de la dialéctica negativa}

Habíamos adelantado que Adorno expone el problema moral a través de tesis contradictorias, que reaparecen como uno de los motivos centrales de la Dialéctica Negativa. Si recapitulamos lo que hemos analizado hasta aquí, vemos que tenemos una primera tesis que concibe a la moral como modelo del discurso de la servidumbre voluntaria. Luego, nos hemos confrontado con una segunda tesis, opuesta a la primera, que piensa a la reflexión moral como modelo de la crítica social y filosófica. ¿Qué ha pasado entre la una y la otra? ¿Cómo piensa Adorno la unidad de estas dos tesis?

$\mathrm{Al}$ intentar interpretar estas argumentaciones contradictorias que moviliza Adorno aparece una de las clásicas impugnaciones de la dialéctica negativa. Esta impugnación piensa a la dialéctica negativa como un pensamiento auto-destructivo, como una contradicción performativa que sólo puede salvarse a través de su inconfesado trabajo parasitario al interior de las funda-

3 Diego Tatián (2012) explora a partir de Spinoza las implicancias éticas y políticas -en un sentido muy próximo al que sugerimos aquí en Adorno- de esta relación entre la generosidad y el principio de irreciprocidad. 
mentaciones universalistas de la razón. En el caso particular del problema moral, lo que sucedería entre ambas tesis sería la corrección recíproca entre los extremos, a través de la negación determinada y parcial del contenido de la fundamentación racional. La primera tesis rechaza ese contenido, mostrando su vínculo necesario con efectos que la contradicen, esto es, con la servidumbre y la injusticia que se esconden detrás de la ley moral; pero lo hace para que luego aparezca una segunda tesis que niega la negación abstracta de las pretensiones de validez de la ley moral, mostrando que ésta aún puede ser ejercida y sigue siendo un modelo para la crítica. La dialéctica negativa no sería sino el procedimiento que consiste en negar lo universal de la razón abstracta para luego negar la negación abstracta de esa universalidad. ${ }^{4}$ ¿No estamos aquí frente a una especie de resultado, que surge del pasaje a través de esa vertiginosa negatividad que Adorno convoca incansablemente en su escritura? El reconocimiento de la imposibilidad actual de fundamentar en términos abstractos la moralidad, junto con la afirmación de la posibilidad de su ejercicio a través de una nueva disposición de la subjetividad moral, ¿no nos enfrenta a la existencia de una tercera tesis, que opera una síntesis entre la primera, que identifica toda moral con la servidumbre y la segunda, que reconoce a la moral como modelo de la crítica?

Este es el punto crucial. No tiene sentido aferrarse a la interpretación que sostiene que el pensamiento en Adorno es incompatible con cualquier "resultado", ya que por ese camino sólo vamos a jugar con tesis contradictorias que se quedan girando en el vacío, como si entre ellas, finalmente, no pasara nada. Por el contrario, debemos aceptar la idea que sostiene que la dialéctica negativa contiene esa tercera tesis mediadora, especialmente cuando nos referimos al problema moral. Vimos que para Adorno la reflexión moral crítica se orienta efectivamente por un imperativo negativo: hacer cesar el sufrimiento físico y psíquico de los otros. Pero el despliegue del contenido de este imperativo negativo no puede ser interpretado como una mera oscilación entre la crítica absoluta y la crítica relativa a las abstracciones universalistas del racionalismo moral. En este punto, la dialéctica negativa tiene que mostrar el camino para una producción normativa diferente.

Voy a proponer pensar a la producción normativa de la dialéctica negativa a través de una aproximación con la reconstrucción que hicieron Menke y Pollmann (2010) de la historia política de los derechos humanos, que incluye sus dificultades, sus dilemas, los problemas de traducción e, inclusive, sus aporías, sin dejar de establecer un conjunto de derechos que afirman una pretensión de universalidad. La reconstrucción que podemos realizar en esta oportunidad de este aspecto de la dialéctica negativa de la moral será necesariamente esquemática, pero servirá para indicar el sentido general de esta producción normativa particular.

Cuando revisamos el significado de la inquietud normativa fundamental de la historia política de los derechos humanos notamos que el mismo se encuentra muy próximo al problema al que nos condujo la reflexión moral de Adorno: ¿cómo puede darse el reco-

4 Schweppenhäuser interpreta la relación de Adorno con el universalismo normativo, inclusive allí donde lo desarma hasta volverlo aporético, como una crítica concreta e inmanente a los logros de la razón discursiva: "Una teoría crítica del universalismo de la filosofía moral comienza por no negar abstractamente la necesaria pretensión de universalidad de los juicios morales; por el contrario, ella formula la idea de su aporía ineluctable. La aporía se nos ofrece a nosotros. Sin la pretensión de universalidad, no tendríamos criterio para el juicio, a pesar de que a partir de este criterio no podamos deducir las acciones empíricas de los individuos empíricos que son compatibles con las normas que son susceptibles de universalización”. Schweppenhäuser (2004), pp. 347-348. 
nocimiento de todos los otros como otros en la fundamentación de derechos?, ¿cómo se pueden evitar la ceguera, la injusticia y la violencia de la moral abstracta de la razón en la fundamentación de esos derechos? La respuesta que encontramos coincide con la reconstrucción que queremos proponer de la tercera tesis de Adorno. De hecho, el modelo que puede responder a esos desafíos interpretativos es el que fundamenta "los derechos humanos en determinados sentimientos, sobre todo en la compasión y la simpatía" (Menke y Pollmann, 2010: 65). También en este caso son estos sentimientos los que hacen posible la afirmación de relaciones solidarias y una consideración del otro que se "toma en serio que los demás sienten y juzgan" según una perspectiva propia de las cosas (Menke y Pollmann, 2010: 66 y ss.). Vemos que ahora la relación mimética con el sufrimiento del otro y la apertura a las perspectivas del otro que esta relación mimética habilita, no están puestas sólo como condiciones negativas o como excepciones a la regla abstracta del reconocimiento racional, sino que sirven como base para la producción normativa de derechos, en este caso, de los derechos humanos. Por esta vía, la simpatía y la compasión devienen pasiones-racionales, que instituyen junto con la capacidad moral de la generosidad las bases inter-subjetivas para una legislación que tiene pretensiones de universalidad. En términos de producción normativa, podemos entender a los derechos humanos como ese tipo particular de derechos hacia los que apunta el juego interno entre pasiones, razones y capacidades que encontramos en la estructura contradictoria de la dialéctica de la moral de Adorno.

Esta apresurada reconstrucción de la tesis "afirmativa" de la dialéctica negativa de la moral sirve para mostrar que lo que Adorno busca con la misma no es volver indecidible o imposible el juicio moral, sino materializar una síntesis provisoria entre dos tesis contradictorias que le da forma a un proceso que Menke ha denominado acertadamente como "politización de la moral" (Menke, 2006a: 167). Este es el objetivo del despliegue y del minucioso trabajo de síntesis de la reflexión crítica sobre la dialéctica del sujeto moral. En tanto síntesis provisoria la dialéctica negativa es capaz de fundamentar producciones normativas definidas a partir de intereses históricos concretos, como lo expresó en su momento el diktum de Adorno: "que Auschwitz no se repita". Esta síntesis provisoria afirma que la reflexión moral siempre se despliega desde el terreno de lo particular, a partir de una temporalidad diferenciada que no tiene su origen último en el sujeto racional, inscribiendo procesos de generalización del otro que reponen el juego de los afectos (empatía con el sufrimiento ajeno) y la capacidad moral de sostener relaciones irrecíprocas (generosidad). Cuando comparamos estas determinaciones con aquellas que reconstruyeron Menke y Pollmann para la historia política de los derechos humanos observamos la enorme proximidad que existe entre ambas constelaciones conceptuales. Bajo esta perspectiva, no sería exagerado interpretar al momento "afirmativo" de la dialéctica negativa de la moral como una búsqueda normativa que tiende a coincidir con el trabajoso recorrido político de fundamentación e institucionalización de los derechos humanos.

Al proponer esta afinidad entre la historia político-institucional de los derechos humanos y la dialéctica de la reflexión moral de Adorno se abren, efectivamente, múltiples problemas interpretativos. Pero lo que debemos destacar aquí es el hecho de que esta producción normativa no se establece en la forma de la actividad ordinaria del juicio, sino que se constituye como una modalidad del pensamiento que repone el carácter político de los conflictos morales, apaciguados normalmente por la cultura dominante. Por lo tanto, cuando aproximamos el momento práctico-afirmativo de Adorno a la historia de los derechos humanos tenemos 
que referirnos muy especialmente a la historia de la lucha por los derechos humanos. En esta lucha las pasiones-racionales (la simpatía y la compasión) han cumplido históricamente un papel enteramente constructivo, ya que son la base de la articulación y la estructuración de esa extraña modalidad de las relaciones intersubjetivas de las que dependen los derechos humanos cuando pretenden extenderse a todos los otros garantizando derechos que pueden basarse para su aplicación en la irreciprocidad. Al interior de esa lucha política por los derechos humanos vemos aparecer articuladas las dos grandes (y contradictorias) preocupaciones morales de Adorno: la inclusión mimética del extraño como igual y la aceptación irrecíproca de las exigencias del otro como otro.

Constatamos ahora por qué en esta producción normativa lo que parecía una falta en términos de universalidad abstracta no asume propiamente el carácter de tal, ya que no se trata de una necesidad lógica que no pudo ser cumplida por la subjetividad que realiza esta reflexión moral. Por el contrario, esa aparente falta de universalidad se transforma en la condición misma de la posibilidad de la politización intersubjetiva de la moral, que tiene como horizonte una forma más compleja y exigente de universalidad. Según la formulación que propone Adorno, la dialéctica de la reflexión moral nos proyecta hacia el espacio de las relaciones políticas entre los seres humanos a partir del imperativo que nos exige intentar hacer cesar el dolor físico y psíquico del otro. Propusimos aquí como ejemplo para pensar esta politización de la moral a las luchas por los derechos humanos. Aquello que nos habilita a pensarlas como modelos de la síntesis práctico-moral que propone Adorno es la centralidad que adquiere en ellas el reconocimiento de derechos que trascienden las fronteras estatales, en un marco moral que exige, al mismo tiempo, respeto hacia la diferencia radical del otro y solidaridad frente a su sufrimiento.

Esta triple condición da lugar frecuentemente a la necesidad de relaciones irrecíprocas, que el pensamiento autoritario detecta y desaprueba -como si se tratara de una injusticiacon una fórmula que se repite con pocas variaciones: "los derechos humanos son sólo para los criminales y los ilegales". Habría que aceptar el desafío de este enunciado del autoritarismo contemporáneo y reconocer en esa apariencia de irreciprocidad la mayor virtud de las luchas por los derechos humanos, ya que de ese modo se vuelven capaces de extender a un plano histórico y político el sentimiento mimético de solidaridad frente al dolor ajeno. Bajo esta perspectiva, los derechos humanos se instituyen como una continuación de la simpatía y la compasión que logra ir más allá de las fronteras de la proximidad y la vecindad jurídicopolítica. Para Adorno, cualquier tentativa de institucionalización de ese tipo de derechos requiere de la gramática de la generosidad y contiene una politicidad inmanente. Este es el significado de la tercera tesis de los modelos de dialéctica negativa referidos a la moral, que Adorno sostiene para poder afirmar también una cuarta tesis.

\section{Paradojas de la moral, la forma de la dialéctica negativa}

La última tesis que encontramos en Adorno referida a la cuestión moral la podemos resumir siguiendo una observación de la dialéctica negativa que sostiene que la reflexión moral es incapaz de comprender conceptualmente la totalidad de lo que sucede en una situación moral. Para que una situación sea susceptible de ser experimentada como una situación que contiene un conflicto moral latente, debe existir algo diferente al pensamiento moral 
y a las pasiones-racionales (simpatía y compasión), que de hecho sea capaz de interrumpir la propia secuencia lógico-discursiva de la reflexión moral. Ese algo, que Adorno designa como lo no-idéntico en el pensamiento, forma parte de la dialéctica de la moral, a pesar de que se encuentra del otro lado del desarrollo discursivo de la reflexión. A esa negatividad de la reflexión moral Adorno lo va a denominar impulso moral:

Los problemas morales se plantean convincentemente no en su asquerosa parodia, la represión sexual, sino en frases como: nadie debe ser torturado, no deben existir campos de concentración. (...) Pero si un filósofo moral se apodera de esas frases y se alegra ahora de haber atrapado a los críticos de la moral citando los valores que él anuncia gozoso, su conclusión clara sería falsa. Verdaderas son esas frases como impulso, cuando se denuncia que en algún lugar se ha torturado. Esas frases no deben ser racionalizadas; como principios abstractos, caerían en seguida en la mala infinitud de su deducción y validez. (Adorno, 1995a: 281)

La cuarta tesis de este modelo de la dialéctica negativa desplaza la cuestión que venimos tratando a partir de una negación que ya no funciona como una simple negación determinada. Ya no se trata de la contraposición entre las pretensiones de principios universales y el ejercicio de reflexiones morales diferentes, implicadas en situaciones políticas y abiertas al juego de las pasiones-racionales. Esta cuarta tesis niega la soberanía de la reflexión moral como tal, entendida como la incesante búsqueda de motivos y argumentos a favor de la validez de un determinado discurso moral (incluido el de los derechos humanos). Ahora ya no se trata exclusivamente de la relación entre pensamientos opuestos, sino de la difícil relación entre un pensamiento y algo que no es un pensamiento; se trata de la unidad conflictiva e irreductible entre la reflexión moral y el impulso moral.

A diferencia de Menke (2006a, 2006b) y Schweppenhäuser (2004), no creo que haya que identificar a los impulsos morales de este movimiento de la dialéctica negativa con los afectos de la compasión y la simpatía, que aparecen nítidamente en el tercer movimiento como las bases de una producción normativa no-conformista. Esas pasiones se pueden combinar adecuadamente con las justificaciones de la reflexión moral; los impulsos morales, en cambio, inscriben una nueva temporalidad y una nueva materialidad en la moral. En este pasaje queda claro que para Adorno los impulsos morales no preparan, ni trabajan como presupuestos de una fundamentación menos abstracta de la moral, sino que, por el contrario, interrumpen, como ráfagas que provienen de las urgencias de la praxis, cualquier actividad de justificación. Adorno tensiona aquí radicalmente al pensamiento moral. Los impulsos morales son más y algo diferente que la simple compasión por los cuerpos torturados, porque donde existen no se proyectan hacia la enunciación de un imperativo general, sino que deciden inmediatamente sobre la acción. Frente a la tortura o los campos de concentración sería aberrante buscar argumentos para actuar o esperar a que la coordinación de los criterios de validez se solidifique con relación a esos afectos particulares.

Esto no significa, sin embargo, que los contenidos que reconstruimos en las tesis anteriores queden "anulados". Las particularidades afirmadas en la segunda y la tercera tesis permanecen en este último movimiento de la dialéctica negativa de la moral, sólo que permanecen más allá de lo que establece su síntesis ideal. Se puede pensar a este cuarto movimiento de 
la dialéctica negativa como una apertura y como otro punto de vista sobre esa posición en la que se habían fusionado en un resultado normativo el pensamiento moral y las pasionesmorales. Con esta cuarta tesis de la dialéctica negativa aparece una nueva materialidad (los impulsos morales) y una nueva relación, que nos va a obligar a pensar una "unidad sin síntesis". Esta unidad sin síntesis, sin embargo, requiere haber atravesado el momento anterior de la síntesis ideal, porque es en relación con ella que aparece la negatividad de los impulsos morales que Adorno quiere redimir en su filosofía moral.

La unidad sin síntesis es la forma que encuentra Adorno para expresar la relación que quiere clarificar entre la síntesis del tercer movimiento del pensamiento moral y los impulsos morales. En esta interpretación de Adorno, entre ellos "no existe ninguna síntesis, porque su unidad sólo existe en los extremos: en el impulso espontáneo que, impaciente con el argumento, no está dispuesto a tolerar que el dolor perdure; y en la consciencia teórica no aterrorizada con las órdenes, que no concibe la razón de que las cosas sigan así todavía indefinidamente" (Adorno, 1995a: 282-283). Así realiza este modelo de la dialéctica negativa la reflexión sobre la moral, invitándonos a transformar a la filosofía en la expresión del dolor del mundo individual y colectivo, empujando al concepto más allá del concepto.

\section{Referencias}

ADORNO, Theodor (1995a): Negative Dialektik, en GS6, Suhrkamp, Frankfurt am Main. ADORNO, Theodor (1995b). Minima Moralia, en GS4, Suhrkamp, Frankfurt am Main.

ADORNO, Theodor (2001): Problems of moral philosophy, Stanford University Press, California.

ADORNO, Theodor y HORKHEIMER, Max (1994): Dialéctica de la Ilustración, Trotta, Madrid.

FORST, Rainer (1996): Kontexte der Gerechtigkeit, Suhrkamp, Frankfurt am Main.

FORST, Rainer (2015): La injusticia de la justicia: la dialéctica normativa según Ibsen, Cavell y Adorno, en: "Justificación y crítica”, Katz, Buenos Aires.

FREUD, Sigmund (1996): El malestar en la cultura, en: Obras completas XXI, Amorrortu, Buenos Aires.

HABERMAS, Jürgen (1994): Conciencia moral y acción comunicativa, Planeta, Barcelona. HABERMAS, Jürgen (1998): Between Facts and Norms, MIT Press, Cambridge.

HABERMAS, Jürgen y RAWLS, John (1998): Debate sobre el liberalismo político, Paidós, Barcelona.

HONNETH, Axel. (2014): El derecho a la libertad, Capital intelectual, Buenos Aires.

KANT, Immanuel (2000): Crítica de la Razón práctica, Alianza, Madrid.

KANT, Immanuel (1990): Observaciones acerca del sentimiento de lo bello y de lo sublime, Alianza, Madrid.

KANT, Immanuel (1995): Fundamentación de la metafísica de las costumbres, Porrúa, México.

LÓPEZ ÁLVAREZ, Pablo (2001): El sujeto impropio. Identidad, reconocimiento y autonomía, Revista Logos, $\mathrm{n}^{\circ} 34,23-43$.

MENKE, Christoph (2006a): Zur Metakritik der praktischen Vernunft II, Kritik der "abstrakten Moralität”, en: "Theodor Adorno Negative Dialektik", Akademie, Berlín. 
MENKE, Christoph (2006b): Reflections on equality, Stanford University Press, California. MENKE, Christoph y POLLMANN, Arnd (2010): Filosofía de los derechos humanos, Herder, Barcelona.

SCHWEPPENHÄUSER, Gerhard (2004): Adorno's Negative Moral Philosophy, en: “The Cambridge companion to Adorno", Cambridge University Press, Cambridge.

TATIÁN, Diego (2012): Spinoza, el don de la filosofía, Colihue, Buenos Aires.

ZAMORA, José (2003): "Th. W. Adorno y la aniquilación del individuo", Revista Isegoría, $\mathrm{n}^{\mathrm{o}} 28$, pp. 231-243.

ZAMORA, José (2010): H. Arendt y Th. Adorno, pensar frente a la barbarie, Revista Arbor, $\mathrm{n}^{\mathrm{o}} 742,245-263$.

ZAMORA, José y MAISO, Jordi (2012): Teoría crítica del antisemitismo, Revista Constelaciones, $\mathrm{n}^{\circ} 4,133-177$. 
